\title{
EVOLUTION OF THE FIRM SIZE DISTRIBUTION IN TURKEY
}

\author{
TÜRKIYE'DE FIRMA BÜYÜKLÜK DAĞILIMININ EVRIMİ
}

\author{
Yiğit AYDOĞAN*
}

\begin{abstract}
Evolution in economics has been treated mainly as a theoretical journey. The methodological difficulties reside in strict assumptions in order to maintain a tractable model for firm dynamics. Agent-Based Computational modeling could be an important breakthrough for evolutionary applications. However, these models rely on deep interpretations of the complete data. In this study, in depth analysis of Turkish firm level data has been presented with an evolutionary point of view using the method of density estimations. The comprehensiveness of the data is unique to the literature. For modeling purposes, Turkish firms could be seen as representing their birth era. The stagnant nature of firms could also be considered as linked to the lack of managerial delegation in underdeveloped economies.
\end{abstract}

Keywords: Evolution, Selection, Firm Dynamics, Firm Size Distribution.

Öz

Ekonomi literatüründe evrim genellikle teorik yaklaşımlarla değerlendirilir. Firma dinamiklerinin modellenmesinde karşılaşılan yöntemsel zorluklar işlevsel modeller oluşturmak için kullanılan sıkı varsayımlardan kaynaklanmaktadır. Ajan Bazlı Kompütasyonel modeller evrimsel uygulamalarda yeni bir atılım oluşturabilir. Ancak bu modeller bütüncül verilerin derinlemesine incelenmesi ve açıklanmasına dayanır. Bu çalışmada Türkiye’deki firmaların büyüklük dağılımları evrimci literatüre uygun şekilde yoğunluk tahmin modellemeleri ile detaylı olarak incelenmiştir. Veri büyüklügü ve kapsayıcılığı açısından literatürde örneği bulunmamaktadır. Modelleme açısından Türk firmalarının kuruldukları dönemin doğasını yansitıyor olabileceği ya da dönemsel firma karakteristiklerinin muhtemel olduğu gösterilmiştir. Firmaların süreklilik arz eden doğaları gelişmemiş ekonomilerde gözlenen yönetimsel delegasyon eksikliğine de bağlanabilir.

* Kirklareli University, Department of Economics, E-mail: yigit.aydogan@klu.edu.tr 
Anahtar Kelimeler: Evrim, Seçilim, Firma Dinamikleri, Firma Büyüklük Dağılımı.

\section{MICRO DATA IN MICROECONOMICS: AN INTRODUCTION}

Economic research is continuously moving towards a highly computerized and statistics based direction, as one might expect by looking at the new millennium's offerings on CPU power. Introducing multidisciplinary areas and flooding researchers from engineering backgrounds during the 1980s and 1990s created a boom on (perhaps unnecessarily) ambiguous mathematical models and crowded journals with more numbers than words. This quantitative expansion might misleadingly make young readers to think of the preceding work in economics is less important and the new economics has just been invented, as Piketty (2000) specifically points out by referring to the Pareto coefficients has been treated as old-fashioned.

The motivation behind conducting research on the firm size distribution has not been debated clearly in the literature. It has been treated as a topic under industrial organization, lacking a bodied theoretical background. Its output is being appreciated by policymakers and courts when needed. Indeed, it is important to know the industry, analyze market shares and draw upon when regulating mergers and acquisitions. This looks like an underestimation considering the possible offerings of the analysis at hand. With the availability of firm level data with complete coverage of the population, more traditional techniques such as distributional plots and graphical analysis might offer insights. It benefits the performance of the economy in several ways. In policy-making, the government needs to base its actions on accurate understanding of the data when choosing from policy options targeting specific firm types. Correctly assessing the nature of entering and exiting firms signal the expected outcome of any step taken. Moreover, certain age groups or cohorts of firms might have different stories to learn from. Lessons from such groups lead communities to a better economic future by avoiding similar mistakes.

Whether static or dynamic, ideas on firm theory can be built and backed with econometric explanations. But when those ideas taken to comprehensive data exampled by this study, one would see the complexity of the evolution of firm sizes might need simpler pillars of action sequences. Complex outcomes do not necessarily originate from equally complex procedures. Agent-Based Computational (ABC) modeling of a virtual economy consists of daily transactions. These entries depend not on the extreme-or even bounded rationality of entities, but the realistic approaches taken against actual problems bounded with the individual reality. As exampled in Delli et al. (2011) not only the business entities, but the whole economic environment could be formed in 8 basic steps. These steps start with firm's decision on output and labor, vacancies get posted, job applications get done and contracts occur. When finances of firms lack resources to produce, they apply to credit market and after evaluation 
gets credit or not. If fails, workers get laid off, planned output drops. After production, goods market operates with viable distance constraints on consumers. After sales, there might be unsold goods remained for the firms and higher than desired prices for the consumers. Profiting firms pay their debts, invest in R\&D, distribute dividends. With possible unpaid loans, banks get non-performing loans. With varying profits, firms might add to or lower their net worth. Firms and banks with negative net worth at the end of the period go bankrupt, new firms enter to the economy and a cycle is completed. While incorporating firm dynamics and industry evolution, this model also accounts for the inflation, business cycles and other macro phenomenon yielding the term bottom-up macroeconomics.

The extremely straightforward but flexible environment of $\mathrm{ABC}$ modeling relies on strong relations to the data, offering a prospect future in economic theory. Building up an $\mathrm{ABC}$ model does not demand extensively mathematical proofs, or vague equation systems, but simulated computerized environments for agents to interact within. The validity of such models are dependent on accurate and detailed observations which goes beyond sorting and regressing limited samples. All of the actions depend on simple, practical and far from fully-rational decision-making procedures. No matter how plausible to the mind - or to the math, each economic environment has its special dynamics which should be taken into considerations prior to modeling. If the aim is to capture the spirit of businesses, building concrete models must depend on not only a snapshot of an industry but an evolutionary mapping. This framework should capture the actual history of majority of the subjected firms. In this study, Turkish business entities between 2005 and 2016 are exhaustively surveyed with a data oriented perspective. The unprecedented exhaustive dataset and sifting out highly useful characteristics of agents while providing benchmarks for computational modeling of Turkish economy are the key contributions of this work. Until now, Turkish firm size distribution were examined in several ways (Pek, 2012; Aydogan and Donduran, 2018), but not with an evolutionary perspective. The hope on the span of the data and diversity of the inferences lay a cornerstone for the next step of desired modeling.

The aim of this study is to analyze the Turkish firms with a genuine evolutionary perspective. The previous literature uses small sections of industries to overcome data handling difficulties. Here, the focus is on the aggregate selection mechanism in the economy. To the best of our knowledge, complete data usage to evaluate selection in firm dynamics is absent in the literature. Moreover, this study should lay out findings to be useful for policy-makers when they need to choose between small or large firms in order to promote further growth.

The raw data of nearly 3.5 million firms per year from 2005 to 2016 is handled by two dynamic and multi layered points of view in the two sections following a literature review. The first angle consists of entering and exiting firms to and from Turkish economy during the subjected period. Additionally, age statistics of the firms went out of business is incorporated to the analysis. For the second part, the firms in each period get divided into 6 age groups, 
i.e.: $0-1,2-4,5-9,10-19,20-29,30$ or more years in business. Both type of analysis is enriched by visualization and density estimations are plotted in a dynamic manner. In the last part, concluding remarks and inferences from the evolution of Turkish firms is made together with references to the contemporary literature.

\section{LITERATURE REVIEW}

Evolutionary studies on firm theory do not reach back in time. Among the pioneers, Jovanovic (1982) shows that firms learn about their individual abilities and evolve towards an efficient size. This evolution is said not from a scarcity of capital but a self-discovery of firms about their talents. The findings come with the claim that smaller firms exit the industry, while efficient ones grow and survive. Supporting the claim of learning through the business process, Evans and Leighton (1989) further asserts that the probability of being an entrepreneur does not depend on age or experience on a job, and in seven years, almost $50 \%$ of undertakers switch back to paid work.

Later work by Audretsch and Mahmood (1994) and Audretsch and Mata (1995) propose an efficient size for firms to achieve in order to survive, while those who could not fail and exit. Combining results with claims from Lucas (1978) they all find it plausible that selection occurs, even if one might not already observe. Firm sizes agreed to be skew towards smaller ones but this is, as claimed, not due to stagnant survivors of smaller firms but continuing the entry of such size groups.

Cabral and Mata (2003) build their model of industry evolution on the financial constraints that a firm faces due to social status, or contacts, of the entrepreneur. In order to overcome a venture, either the owner needs to possess some wealth, or achieve equivalent financing opportunities. Besides, selection is assumed to play a little role. On the other hand, Angelini and Generale (2008) claim that importance of the financial constraints on the firm size distribution is relatively lower in financially developed countries while highly significant in non-OECD countries.

There is a sizeable amount of literature on evolution of the firm size distribution focusing on institutional factors (e.g. Henrekson and Johansson, 1999; Box, 2008; Capelleras and Rabetino, 2008; Acemoglu, 2012; Galor and Michalopoulos, 2012). Building up a Labor Market Regulation Index for 24 low and 20 high income countries for the period 1965-1999, Kilıçaslan and Taymaz (2009) have found that high labor market flexibility and weak regulations interrupt selection process for less productive firms in developing economies such as Turkey. Similarly, Akcigit, Alp and Peters (2016) assert that selection lacks in non-developed economies. It was observed that many small firms nevertheless survive in such economies which possess a problem in terms of theory, comparing the US and Indian firm data. They find that in developing economies people run businesses not always seeking growth and prosperity, 
but for subsistence. Therefore, they lack incentives to incorporate managerial talent from outside. This choice of not growing is said to be also originated from the difficulties of delegating managers which firm needs. Considering the founding era as a determinant of firm performance, Geroski, Mata and Portugal (2010) assert that firms' survival significantly depends on the neonatal conditions.

\section{DATA}

There are several size definitions for business firms in the economic literature, starting with the employment count (Gibrat, 1931). Size can also be considered as sales (Cefis, Ciccarelli and Orsenigo, 2002), assets (Serrasqueiro et al., 2010), revenue (Tang, 2015), output and value added (Harris and Trainor, 2005). Nevertheless, many studies which employ multiple data sets confirm that the definition of the size does not alter the outcome (Axtell, 2001; Daunfeldt and Elert, 2013; Tang, 2015). So it can be said that the more complete data is the best to be used, which is employment in the case of Turkey.

Table 1: Summary Statistics of Turkish Firms, 2005-2016

\begin{tabular}{ccccccc} 
Year & Median & Mean & 3rd-Q & Max & \#Firms & \#Employees \\
\hline $\mathbf{2 0 0 5}$ & 1 & 3.1 & 1 & 40,393 & $3,455,700$ & $10,678,113$ \\
$\mathbf{2 0 0 6}$ & 1 & 3.1 & 1 & 59,146 & $3,205,948$ & $9,842,260$ \\
$\mathbf{2 0 0 7}$ & 1 & 3.4 & 1 & 43,555 & $3,175,493$ & $10,796,676$ \\
$\mathbf{2 0 0 8}$ & 1 & 4.3 & 1 & 64,000 & $3,490,786$ & $15,010,380$ \\
$\mathbf{2 0 0 9}$ & 2 & 4.1 & 2 & 101,386 & $3,227,238$ & $13,070,314$ \\
$\mathbf{2 0 1 0}$ & 1 & 3.8 & 1 & 30,724 & $3,003,116$ & $11,291,716$ \\
$\mathbf{2 0 1 1}$ & 1 & 4.1 & 2 & 83,700 & $3,422,163$ & $14,065,090$ \\
$\mathbf{2 0 1 2}$ & 1 & 4.5 & 2 & 31,760 & $3,474,992$ & $15,776,464$ \\
$\mathbf{2 0 1 3}$ & 1 & 5.2 & 3 & 70,679 & $3,529,541$ & $18,459,499$ \\
$\mathbf{2 0 1 4}$ & 1 & 5.4 & 3 & 139,576 & $3,525,431$ & $19,002,073$ \\
$\mathbf{2 0 1 5}$ & 1 & 5.4 & 3 & 27,852 & $3,584,832$ & $19,322,244$ \\
$\mathbf{2 0 1 6}$ & 1 & 5.4 & 3 & 29,309 & $3,652,521$ & $19,650,563$ \\
\hline
\end{tabular}

Source: TURKSTAT - Micro Data Collections

Regarding the Turkish firm statistics, TURKSTAT holds a very comprehensive dataset called "Annual Business Registers Framework" which consists of all registered firms contributing to the GDP of Turkey. Table 1 possesses some statistics on approximately 3.5 million firms per year for the period from 2005 to 2016.

As seen in Table 1 mean firm size in Turkey significantly increased since 2005, by $74 \%$ from 3.09 to 5.38 employees. This increase has not been robust to shocks, however. The hit of Global Financial Crisis in 2009 created a 3-year setback in terms of mean size. More interestingly, median firm size reached to 2 in the crisis year meaning a more symmetrical firm 
size distribution than pre-crisis years. During 2011-2014, firm sizes increase steadily in average but stagnate afterwards. The third quantile in firm size distribution reached 3 from 1 in a decade, noting a general growth in most of the firms in the economy.

Figure 1 depicts firm size distribution in Turkey for the period 2005-2016. It is evident that the overall distribution remained relatively stable, except for the year 2009. There is a critical slope around the firms with 50 or more employees, where the density of the larger firms drops instantly. These statistics and visualization below emphasize that Turkish firm size distribution possesses an increasingly skew distribution as expected, with medians stay further from the mean as the mean rises. According to the literature, a versatile economic environment and efficient firms should carry the lower or at least medium parts of the distribution up. Lack of this situation needs to be diagnosed in order to infer a way out.

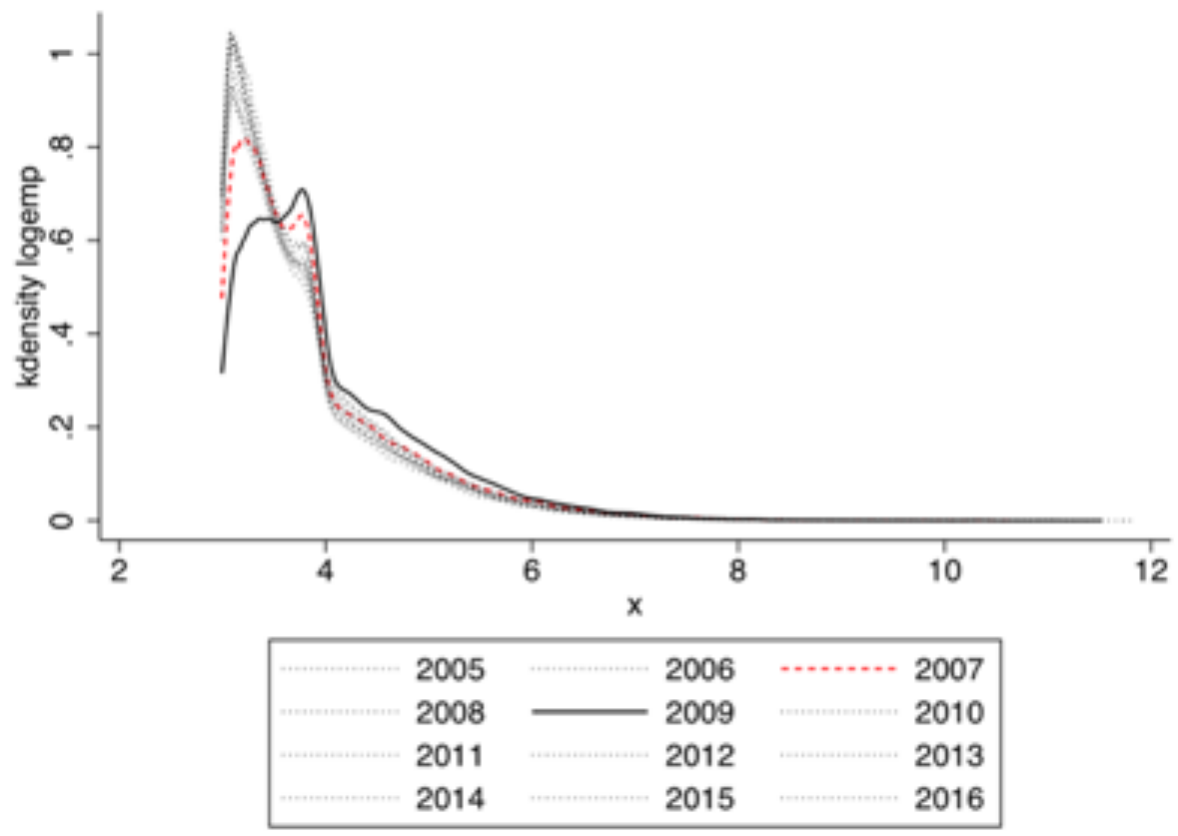

Figure 1. Size Distribution of All Firms, 2005-2016

Source: TURKSTAT - Micro Data Collections

Regarding the sectorial composition of the subjected data set, Table 2 summarizes the selected sections. TURKSTAT reports the Business Registers complying NACE Rev. 1.1 for the period of 2005-2008, and NACE Rev. 2 from 2009 to 2016.

Three sections of Business Registers data are selected for demonstration purposes, which are Manufacturing as the back-bone of modern economies, Construction as a highly debated boosting element of 2000s Turkey, and Trade as the largest part. It is seen from Table 2 that 
Turkish private sector composition gets negatively hit by the Global Financial Crisis in terms of Manufacturing firms, and Construction and Trade sections increased in percentage. Yet, Manufacturing firms regain their share after the crisis years. Interestingly enough, Construction firms increases in share throughout the period, except 2015, which could be subjected in a further study with a focus on sectorial evolution.

Table 2: Shares of Selected Sections in Firm Count, 2005-2016

\begin{tabular}{cccc} 
Year & Manufacturing & Construction & Trade \\
\hline $\mathbf{2 0 0 5}$ & $12.30 \%$ & $4.20 \%$ & $39.50 \%$ \\
$\mathbf{2 0 0 6}$ & $12.70 \%$ & $4.60 \%$ & $39.60 \%$ \\
$\mathbf{2 0 0 7}$ & $12.70 \%$ & $4.80 \%$ & $39.60 \%$ \\
$\mathbf{2 0 0 8}$ & $13.00 \%$ & $5.00 \%$ & $39.70 \%$ \\
$\mathbf{2 0 0 9}$ & $11.90 \%$ & $5.30 \%$ & $40.20 \%$ \\
$\mathbf{2 0 1 0}$ & $11.60 \%$ & $5.30 \%$ & $40.50 \%$ \\
$\mathbf{2 0 1 1}$ & $12.00 \%$ & $6.10 \%$ & $39.50 \%$ \\
$\mathbf{2 0 1 2}$ & $12.20 \%$ & $6.10 \%$ & $38.60 \%$ \\
$\mathbf{2 0 1 3}$ & $13.00 \%$ & $7.20 \%$ & $37.60 \%$ \\
$\mathbf{2 0 1 4}$ & $13.00 \%$ & $7.60 \%$ & $37.10 \%$ \\
$\mathbf{2 0 1 5}$ & $13.20 \%$ & $6.50 \%$ & $37.50 \%$ \\
$\mathbf{2 0 1 6}$ & $12.90 \%$ & $7.70 \%$ & $36.80 \%$ \\
\hline
\end{tabular}

Source: TURKSTAT - Micro Data Collections

\section{EVOLUTION OF THE FIRM DYNAMICS}

The primary forces behind the evolution of the industry are closing firms due to selection and new enterprises emerging with hopes to survive. Entry and exit conditions of firms might possess important information regarding the core functions of the economy. In the economic literature, both entering and closing firms are considered to be small with respect to the overall distribution. A disturbance on this status defines an important characteristic about the subjected economy.

\subsection{Survey of the Firm Dynamics}

The strength of an economy comes from its resilience to shocks, and the key factor to overcome destructive time periods is the capability of keeping the influx of new venturers to the economic environment. This nature of the economy can be observed through the statistics of the entrants. Table 3 provides the business units that got enlisted by the registers during the period 2005-2016. 
Table 3: Size Statistics of Entering Firms, 2005-2016

\begin{tabular}{ccccccc} 
Year & Obs. & Meana & Std.b & b/a & Variance & Skewness \\
\hline $\mathbf{2 0 0 5}$ & 565,364 & 2.2 & 49.2 & 22 & 2421 & 595 \\
$\mathbf{2 0 0 6}$ & 465,124 & 1.8 & 23.8 & 13 & 567 & 378 \\
$\mathbf{2 0 0 7}$ & 427,475 & 3.9 & 82.9 & 21 & 6880 & 138 \\
$\mathbf{2 0 0 8}$ & 273,048 & 2 & 8.5 & 4 & 72 & 91 \\
$\mathbf{2 0 0 9}$ & 246,856 & 2.1 & 14 & 7 & 197 & 167 \\
$\mathbf{2 0 1 0}$ & 97,494 & 1 & 0.2 & 0 & 0 & 133 \\
$\mathbf{2 0 1 1}$ & 343,529 & 2.2 & 64.5 & 29 & 4159 & 392 \\
$\mathbf{2 0 1 2}$ & 117,459 & 4 & 43.5 & 11 & 1890 & 245 \\
$\mathbf{2 0 1 3}$ & 372,920 & 2.8 & 86.3 & 31 & 7442 & 559 \\
$\mathbf{2 0 1 4}$ & 445,292 & 2.5 & 14.6 & 6 & 213 & 45 \\
$\mathbf{2 0 1 5}$ & 411,093 & 2.9 & 18.5 & 6 & 343 & 48 \\
$\mathbf{2 0 1 6}$ & 461,834 & 2.4 & 17.7 & 7 & 314 & 83 \\
\hline
\end{tabular}

Source: TURKSTAT - Micro Data Collections

New firm formations play crucial role in overall economic prosperity. There is a significant higher level of innovation comes from the entering firms, rather than the older business entities, favoring also the higher size (Huergo and Jaumandreu, 2004). Although the starting and ending values are close, Table 3 depicts a significant variance of the new establishments mean size over the years. Mean size of the new firms turned out to be especially low in 2006, 2008 and 2010. On the other hand, mean size of entrants in 2007 and 2012 are close to 4 , former being higher than the overall mean of the economy. This is a peculiarity because the small size of the entrants is an important common pre-acceptance carried by almost all firm dynamics research.

Total number of newly formed businesses also varies during the period. While entrant count stayed moderately low in 2008 and 2009, it was shockingly stayed below a hundred thousand in 2010. It is surprising due to the notion that more firms were supposed to be added after a crisis year to seize the opportunity. The year 2010 formed a deadlock of Turkish businesses by such a low number of firms with a mean of 1, compressed with an extremely low variance. As a final remark, year 2012 possesses a very low number of entrants just above 2009 , yet their mean is nearly equal to the overall distribution of firms.

Table 4 possesses information on the firms which got out of business during the period 2005-2016 ${ }^{1}$. In theory, closing firms should rather be small in size and this is mostly verified by the Turkish firm data. Again in 2010, the smallest of the closing firm sizes occur with a small variance. A higher mean size of closing firms than the mean size of entrants depicts an unfavorable picture, further lowering the overall mean of firm sizes. Although the total number of entrants and closing firms differ a lot, this statistic lays the general climate about the economic outlook.

1 Data of 2006 is in limited scope due to a collection problem. 
Table 4: Size Statistics of Closing Firms, 2005-2016

\begin{tabular}{ccccccc} 
Year & Obs. & Meana & Std.b & b/a & Variance & Skewness \\
\hline $\mathbf{2 0 0 5}$ & 250,533 & 1.7 & 23.4 & 14 & 547 & 94 \\
$\mathbf{2 0 0 6}$ & 705 & 49.1 & 346.1 & 7 & 119763 & 18 \\
$\mathbf{2 0 0 7}$ & 74,146 & 2.7 & 45.4 & 17 & 2065 & 78 \\
$\mathbf{2 0 0 8}$ & 50,060 & 13.5 & 125.3 & 9 & 15693 & 56 \\
$\mathbf{2 0 0 9}$ & 183,545 & 2.6 & 39.5 & 16 & 1558 & 367 \\
$\mathbf{2 0 1 0}$ & 214,664 & 1.4 & 6.6 & 5 & 44 & 94 \\
$\mathbf{2 0 1 1}$ & 270,825 & 1.6 & 7.5 & 5 & 56 & 113 \\
$\mathbf{2 0 1 2}$ & 242,045 & 1.9 & 28.5 & 15 & 810 & 418 \\
$\mathbf{2 0 1 3}$ & 270,345 & 2.4 & 137.8 & 57 & 18997 & 499 \\
$\mathbf{2 0 1 4}$ & 245,010 & 2.1 & 14.4 & 7 & 207 & 86 \\
$\mathbf{2 0 1 5}$ & 222,231 & 2.3 & 16.4 & 7 & 269 & 80 \\
$\mathbf{2 0 1 6}$ & 251,483 & 2.8 & 25.2 & 9 & 635 & 67 \\
\hline
\end{tabular}

Source: TURKSTAT - Micro Data Collections

In this notion, Turkish economy could not make up for the spots opened by closing firms in terms of relative size in 2010 and 2016. In 2013, closing firms' distribution varied significantly in terms of size, indicating a widespread hazard problem also for larger firms.

Table 5: Age Statistics of Firms by Year, 2005-2016

\begin{tabular}{ccccccc} 
Year & Obs. & Meana & Std.b & b/a & Variance & Skewness \\
\hline $\mathbf{2 0 0 5}$ & $3,040,531$ & 4.8 & 5.7 & 1.2 & 31.9 & 2.5 \\
$\mathbf{2 0 0 6}$ & $2,890,595$ & 5.1 & 5.8 & 1.1 & 33.5 & 2.3 \\
$\mathbf{2 0 0 7}$ & $2,928,276$ & 5.3 & 5.9 & 1.1 & 34.7 & 2.3 \\
$\mathbf{2 0 0 8}$ & $3,182,797$ & 6 & 7.1 & 1.2 & 50.5 & 4.1 \\
$\mathbf{2 0 0 9}$ & $3,182,797$ & 7 & 7.1 & 1 & 50.5 & 4.1 \\
$\mathbf{2 0 1 0}$ & $2,968,474$ & 8.7 & 8.7 & 1 & 76.3 & 5.5 \\
$\mathbf{2 0 1 1}$ & $3,344,796$ & 8.3 & 9.1 & 1.1 & 82.6 & 4.9 \\
$\mathbf{2 0 1 2}$ & $3,173,469$ & 10.6 & 8 & 0.8 & 64.6 & 1.2 \\
$\mathbf{2 0 1 3}$ & $3,529,165$ & 7.9 & 7.4 & 0.9 & 54.5 & 1.6 \\
$\mathbf{2 0 1 4}$ & $3,525,430$ & 7.6 & 8.2 & 1.1 & 67.1 & 3.2 \\
$\mathbf{2 0 1 5}$ & $3,311,021$ & 7.7 & 9.3 & 1.2 & 86.6 & -189.5 \\
$\mathbf{2 0 1 6}$ & $3,652,521$ & 7.8 & 8.3 & 1.1 & 68.6 & 2.4
\end{tabular}

Source: TURKSTAT - Micro Data Collections

Firms in a stable economic environment enjoy a long life cycle, depending on their individual capabilities. In terms of growth, older firms are shown to be more stable (Evans, 1987b) and more robust to shocks (Evans, 1987a; Adelino, Ma and Robinson, 2017). According to Table 5, Turkish firms were young in 2005 with a mean of 4.8 years, showing a steady aging to a mean of 10.6 in 2012. Post-crisis period shows a sudden increase in age, backing the theory of resilience of older firms to shocks. Between 2013 and 2016, combining 
with Table 3, influx of new firms kept the mean age lower. The year 2012 marks an important symmetrical age distribution, reflecting the sweeping of the crisis on younger firms. 2

Table 6: Age Statistics of Closing Firms, 2005-2016

\begin{tabular}{ccccccc} 
Year & Obs. & Meana & Std.b & b/a & Variance & Skewness \\
\hline $\mathbf{2 0 0 5}$ & 233,925 & 3.8 & 5.3 & 1.4 & 28.3 & 2.9 \\
$\mathbf{2 0 0 6}$ & 625 & 5.5 & 6.8 & 1.2 & 45.7 & 2.7 \\
$\mathbf{2 0 0 7}$ & 70,878 & 4.9 & 5.6 & 1.1 & 31.4 & 2.8 \\
$\mathbf{2 0 0 8}$ & 49,907 & 7.3 & 8.2 & 1.1 & 67.9 & 4.1 \\
$\mathbf{2 0 0 9}$ & 183,487 & 6.3 & 6.2 & 1 & 38.2 & 3.8 \\
$\mathbf{2 0 1 0}$ & 214,396 & 6.8 & 8.1 & 1.2 & 65.4 & 3.3 \\
$\mathbf{2 0 1 1}$ & 270,562 & 6.5 & 8.3 & 1.3 & 68.2 & 3.5 \\
$\mathbf{2 0 1 2}$ & 241,499 & 9.3 & 7.8 & 0.8 & 61.4 & 1.4 \\
$\mathbf{2 0 1 3}$ & 270,341 & 6.1 & 7 & 1.1 & 48.5 & 2 \\
$\mathbf{2 0 1 4}$ & 245,010 & 5 & 7.1 & 1.4 & 49.7 & 14.3 \\
$\mathbf{2 0 1 5}$ & 222,231 & 4.7 & 6.6 & 1.4 & 43.9 & 2.6 \\
$\mathbf{2 0 1 6}$ & 251,483 & 4.9 & 6.6 & 1.4 & 43.6 & 2.4 \\
\hline
\end{tabular}

Source: TURKSTAT - Micro Data Collections

Despite the nourishing nature of economic environment in any country, firms get out of business all the time. Distribution of these firms' ages signals different drawbacks. It is seen in Table 6 that mean age of firms that went out of business during the period 2005-2016 changes significantly. Average age of closing firms rose from 3.81 to 4.88 in twelve years, but it reached a shocking maximum of 9.27 in 2012. The period of 2009-2013 constitutes a massive shutting down of grown up businesses with respect to overall age distribution in Turkey.

As noted before, closing firms should be picked by selection. Combining Tables 4 and 6 , one can see that such firms were long lived despite their small sizes. This supports the claim of Akcigit et al. (2016) regarding the business ownership for subsistence, hence lacking incentives to grow. Yet these firms could had been enjoying the easing access to credit during the 2000s (Ayyagari et al., 2016), and deterred the inevitable end, while efficient firms with easy financing grows to the future (Beck and Demirguc-Kunt, 2006).

2 Skewness and Kurtosis calculations get effected even with a few outliers' data disturbance, as in Table 5 for 2015. 

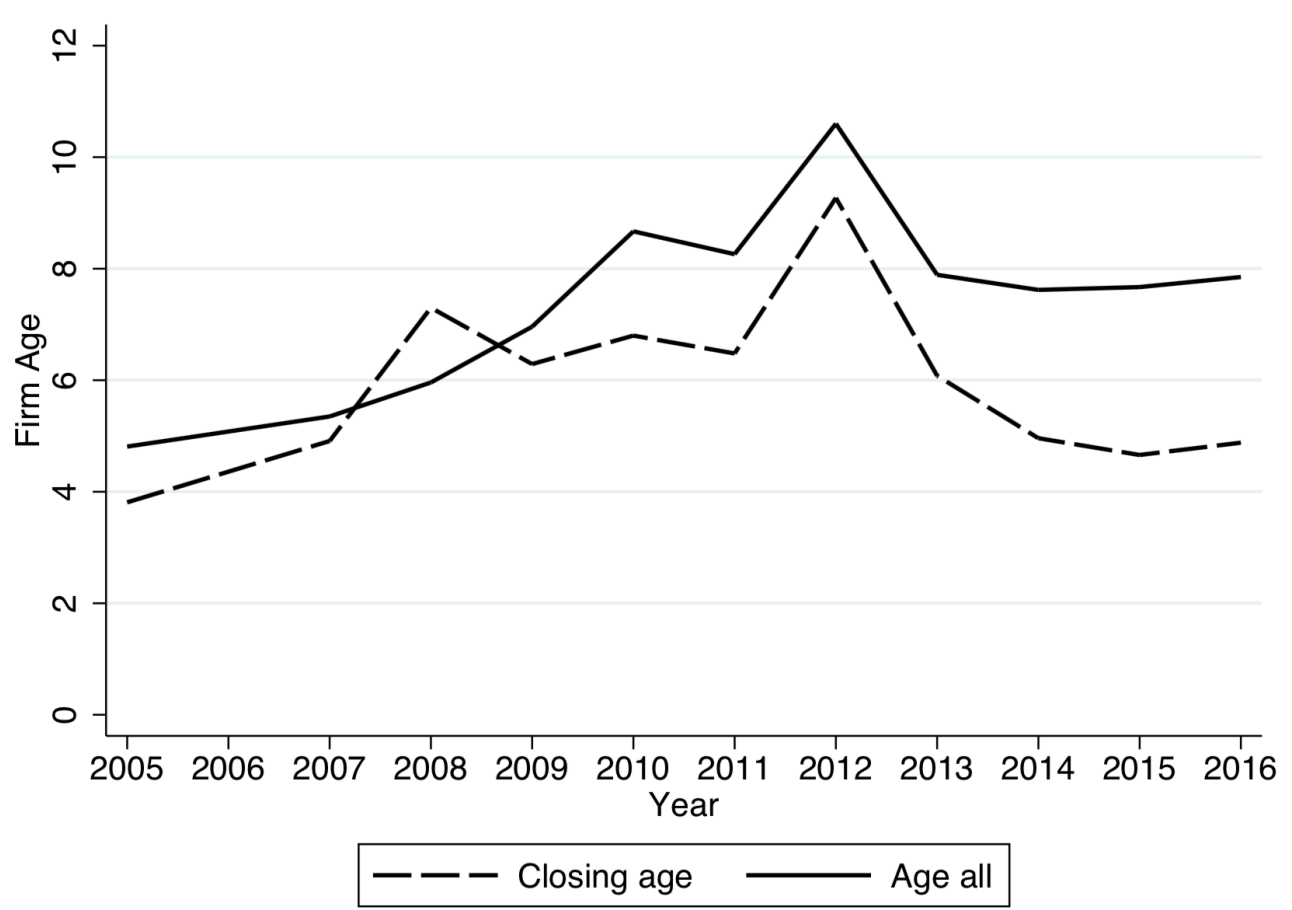

Figure 2. Age and Firm Dynamics, 2005-2016

Source: TURKSTAT - Micro Data Collections

Figure 2 shows the closing firms mean age together with the all firm mean over the period 2005-2016. It is surprising to infer that until recently, selection did not work in Turkish economy building on the fact that closing firms are increasingly older between 2005 and 2012. After 2013, closing firms' age decouples from mean age of all firms.

Figure 3 depicts mean sizes of entering and closing firms within the period of 2005 and 2016. The extreme peak in mean closing firm size of 2008 portrays the severity of the Global Financial Crisis reflections in Turkey. During 2008-2010, not only the larger firms gone out of business, but also entrants mean size was significantly decreased. Entrants' mean size increase sharply during 2011-2012 period signaling a post-crisis boom. A more interesting note on the graph is that in the last year, i.e. 2016, mean size of closing firms are higher than the entrants' which was only the case during the Crisis period. It warns about another possible turmoil in Turkish economy. 


\subsection{Density Estimations}

\subsubsection{Distribution of the Entrants}

Numerical assessments of the previous part deserve visualization for an extra emphasis. Figure 4 depicts the size distribution of firms who enter to the business environment in Turkey between 2005 and 20163 . The lines of consecutive three years are plotted into the same panel to capture year-over-year variance. Figure 4 a shows a disturbance on lower medium to medium size firms. There are significantly more firms entered to the economy in 2005 and 2006, while smaller firms dominate the 2007 cohort.

To assess the effect of the crisis perception, Figure 4b plots 2008, 2009 and 2010 together. It can be seen that the majority of the entrants did not exceed 20 employees in 2008. Yet the larger firms start to be formed in 2009 and 2010. Comparing to other panels and keeping in mind that mean size of entrants equals to 1 in 2010 from Table 3, it can be seen that the weight of the medium-size firms decreased for this period. This might be caused by the discouraging nature of the unfavorable economic environment, letting subsistence-seeking people in but keeping moderately endowed risk averse entrepreneurs. The fading effect of the crisis years can also be seen in Figure 4c. The peak in 2011 at the density of entering smaller firms gets a significant correcting shift in 2012, and almost staying the same in 2013.

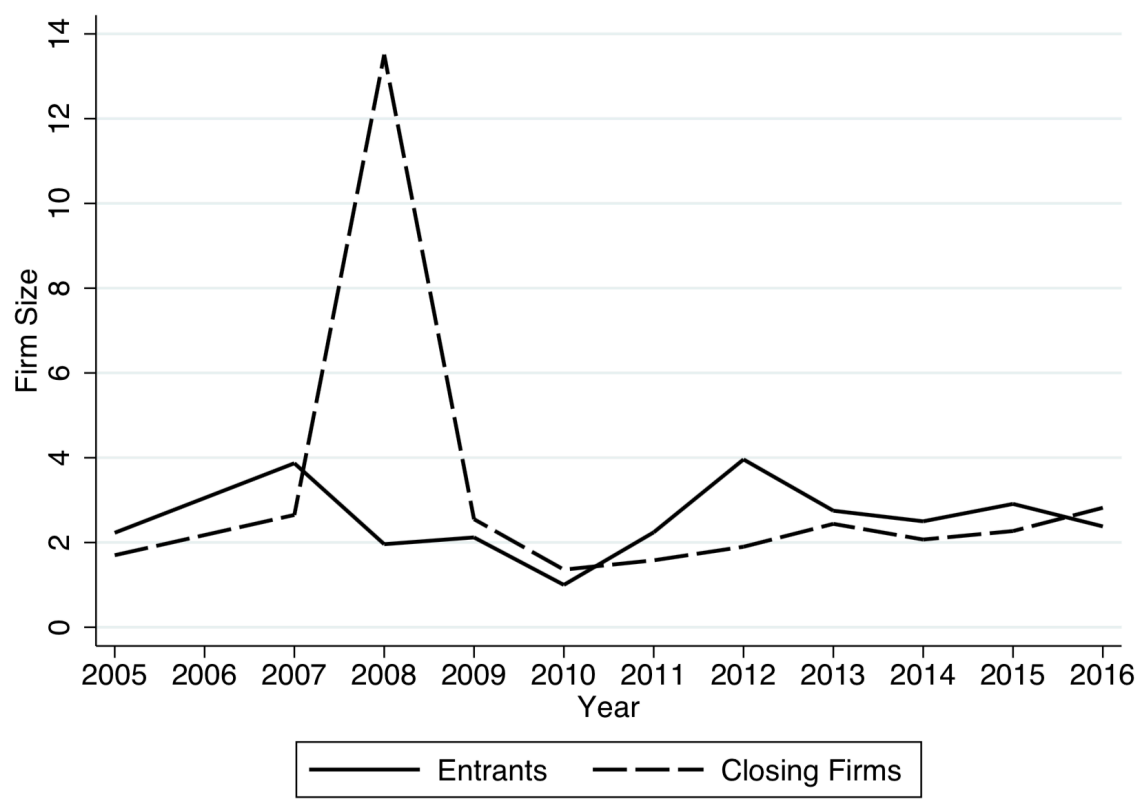

Figure 3. Firm Size and Dynamics, 2005-2016

Source: TURKSTAT - Micro Data Collections

3 To make the distribution plots visually tractable, firms with size 10 and above are considered. 
Figure 4d, on the other hand, depicts another shock towards smaller entrants in 2014, with a more gradual smoothing over 2015 to 2016. But recalling from Table 3, the cluster of smaller entrants in 2014 is much less skewed and sparsely distributed around the middle size firms. This fact lowers the noteworthiness of the visual disturbance observed, at least compared to Figure $4 \mathrm{c}$.

\subsubsection{Distribution of the Closing Firms}

Investigating the distributional properties of closing firms has two major outcomes. First, it helps distinguishing the main reasons that drive the firms out of business during the subjected time period, being a contemporary shock or a structural problem. Second, it reveals the direction of which selection levies on the economic environment, hence allows intervening if the evolution results undesirable outcomes. The lines of consecutive three years are plotted into the same panel to capture year-over-year variance in Figure 5, same as before.

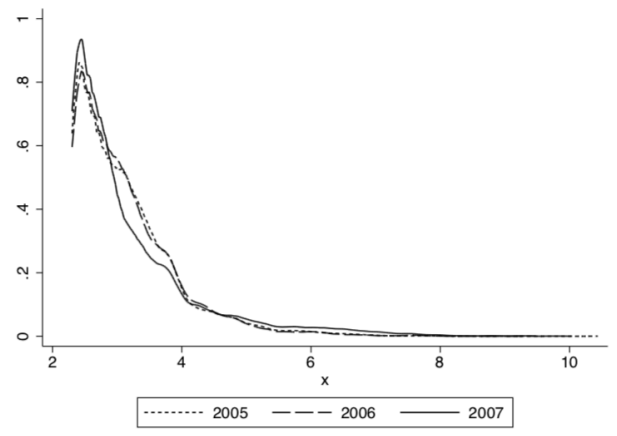

(a)

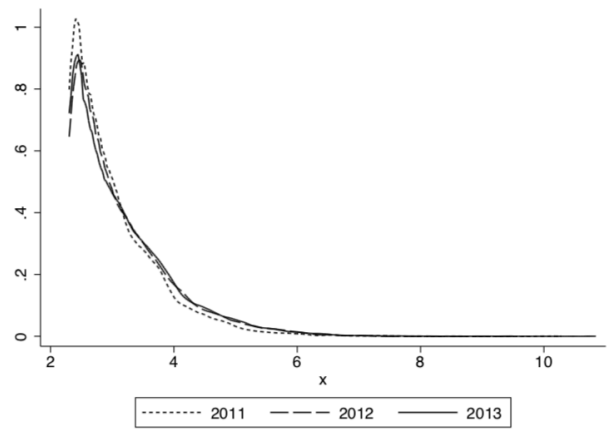

(c)

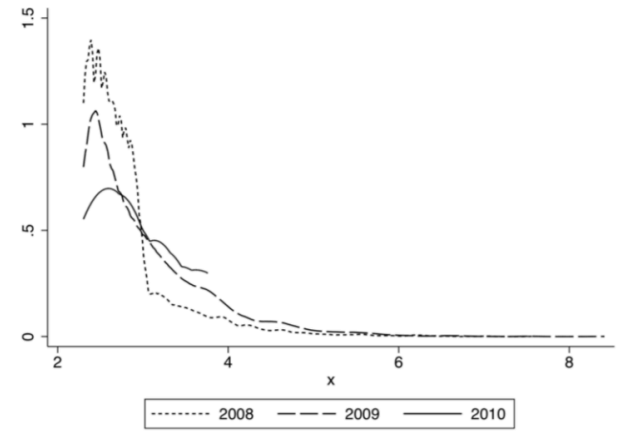

(b)

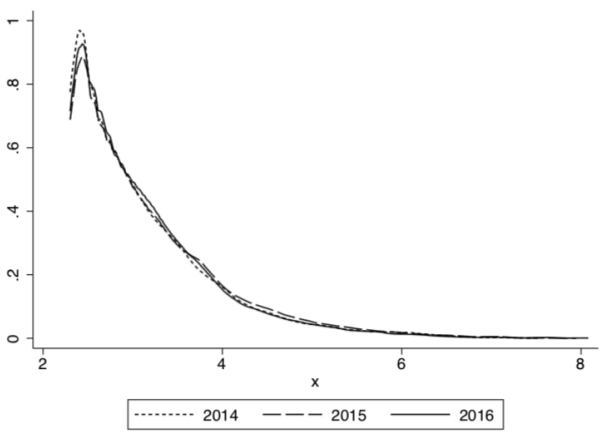

(d)

Figure 4. Size Distribution of the Entrants, 2005-2016

Source: TURKSTAT - Micro Data Collections 
Figure 5a shows a smoothing distribution of closing firms from 2005 to 2007. The concentration of closing sizes is more sparsely distributed than all other years. This observation supports the idea that small and inefficient firms could deter their exit with easing financing opportunities until the crisis. Previously fallen density of smaller firms starts to dominate the distribution from 2008 onwards, as Figure 5b depicts, reaching a high in 2009. Another inference from these two lines would be that moderately sized firms who survived through 2008 , succeeded to sparing themselves also from troubles in 2009. Adapting protection measures from crisis might worked for some of the firms for some time. Figure $5 c$ reverses the order: domination of small firms in closing distribution fades from 2011 to 2013.

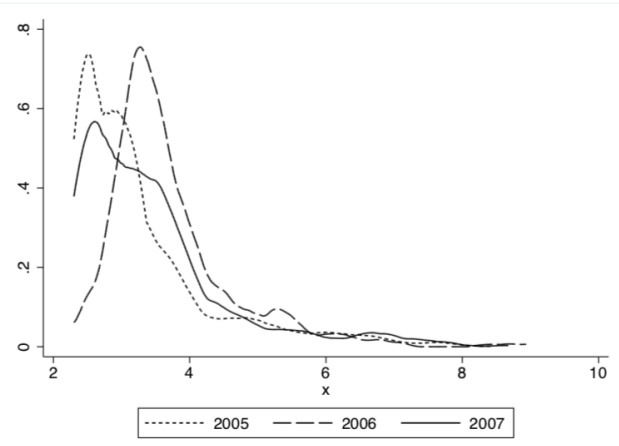

(a)

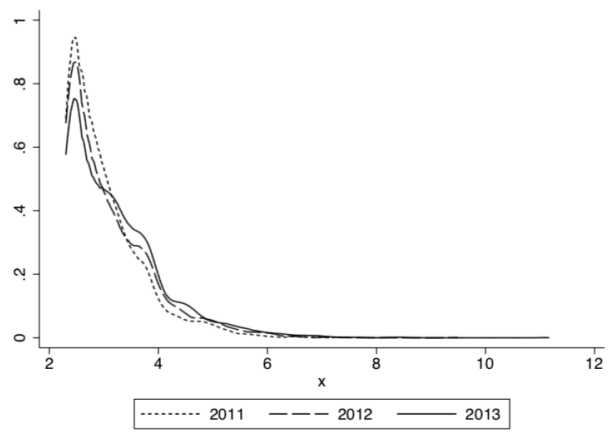

(c)

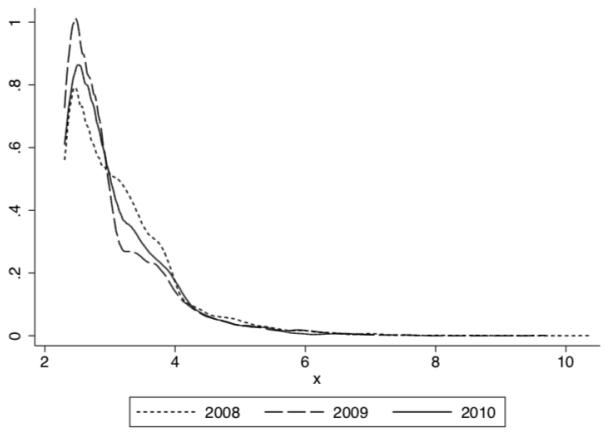

(b)

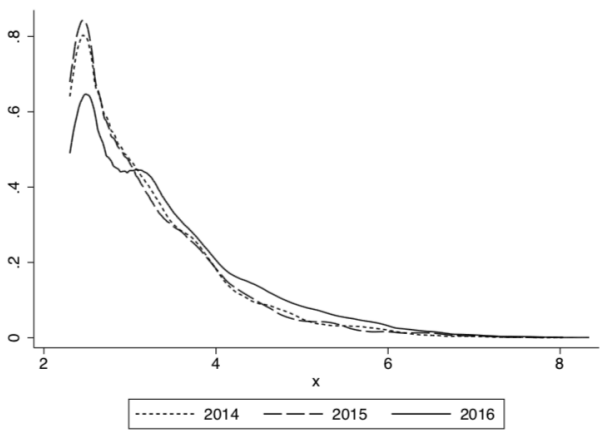

(d)

Figure 5. Size Distribution of the Closing Firms, 2005-2016

Source: TURKSTAT - Micro Data Collections

The similarity of the years 2008 and 2013 are striking. When Figure 5d examined, things about the closing firm size distribution converges back to a similar shape with 2005, but this time with less skewness and more density on the smaller firms as theory predicts. 


\section{AGE AND SIZE DISTRIBUTION OF FIRMS}

Firms of different ages could possess diverse characteristics, both as individuals and groups. The age grouping of Cabral and Mata (2003) is adopted for Turkish firms in the following section for the available data. There are 6 age groups of firms identified. Firms with $0-1,2-4,5-9,10-19,20-29$ and 30 or more years of lifetime are considered to form a cohort. Apart from the yearly changes, the overall evolution of the age groups is inspected. So, from the period of 2005 to 2016, selections of 5 years are to be tabulated in the Section 5.1 and 5.2, namely 2005, 2007-2009, and 2016.

\subsection{Survey of the Age Groups}

Handling the data is crucial in order to extract unique information. Figures 6 and 7 depict the same data with reverted plots. In Figure 6, evolution of each age group can be observed. Line patterns follow the age order from dots to a solid line. In 2005, an interesting disorder of older firms being smaller is observed. This irregularity gets corrected during the Global Financial Crisis and age-size order is kept in line afterwards, backing the claim on the lack of selection in pre-crisis period. The oldest age group, namely 30 and above, is boosted in 2008. The Crisis could be said to hit the small and inefficient old firms severely, and dropping out of this group lets the remaining firms portray a larger mean in terms of size.

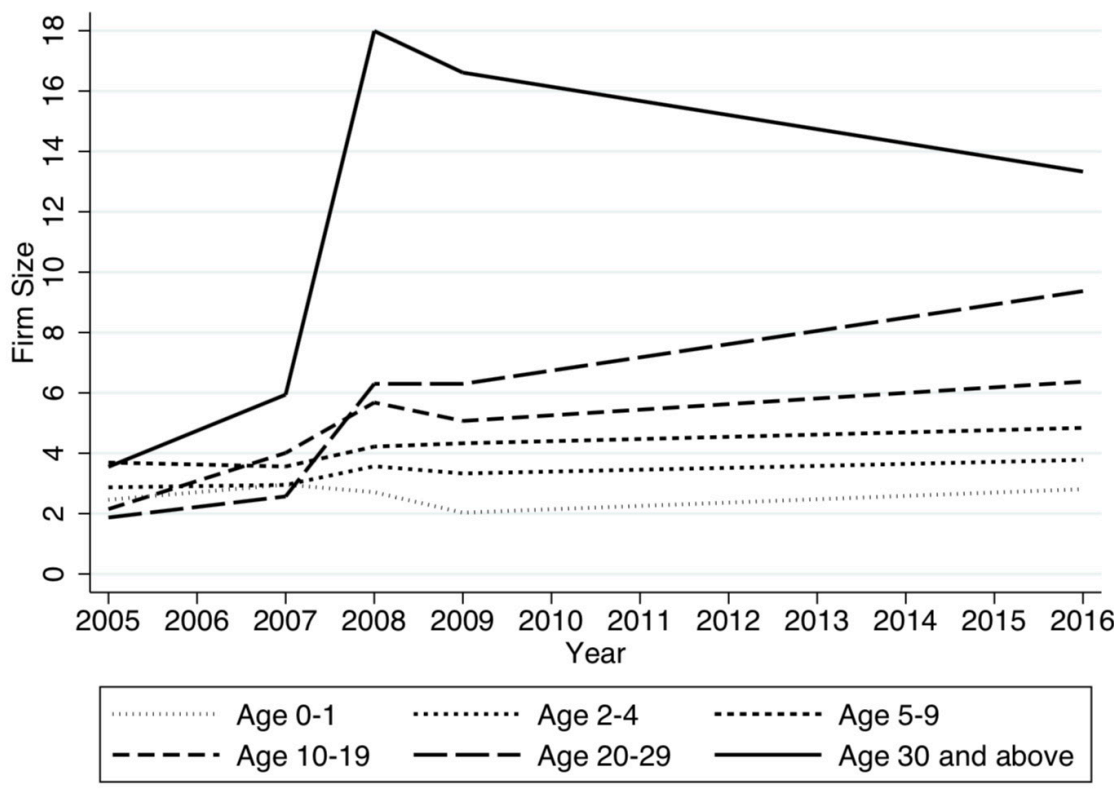

Figure 6. Plot of the Age Groups

Source: TURKSTAT - Micro Data Collections 
In Figure 7, distribution of age groups is presented. It is seen that before the Crisis, Turkish firms were not ordered according to their age in terms of size: older did not mean larger. Especially the age groups of 10 to 19 and 20 to 29 in 2005, and 20 to 29 in 2007 stands out as extraordinarily small in mean size with respect to the younger groups. A shock to the economy can be represented with a kinked age group-size plot of 2008 and 2009, indicating the oldest age group grow in size and create a gap with the successor group. This kinked shape smooths out in 2016 towards a more natural outlook.

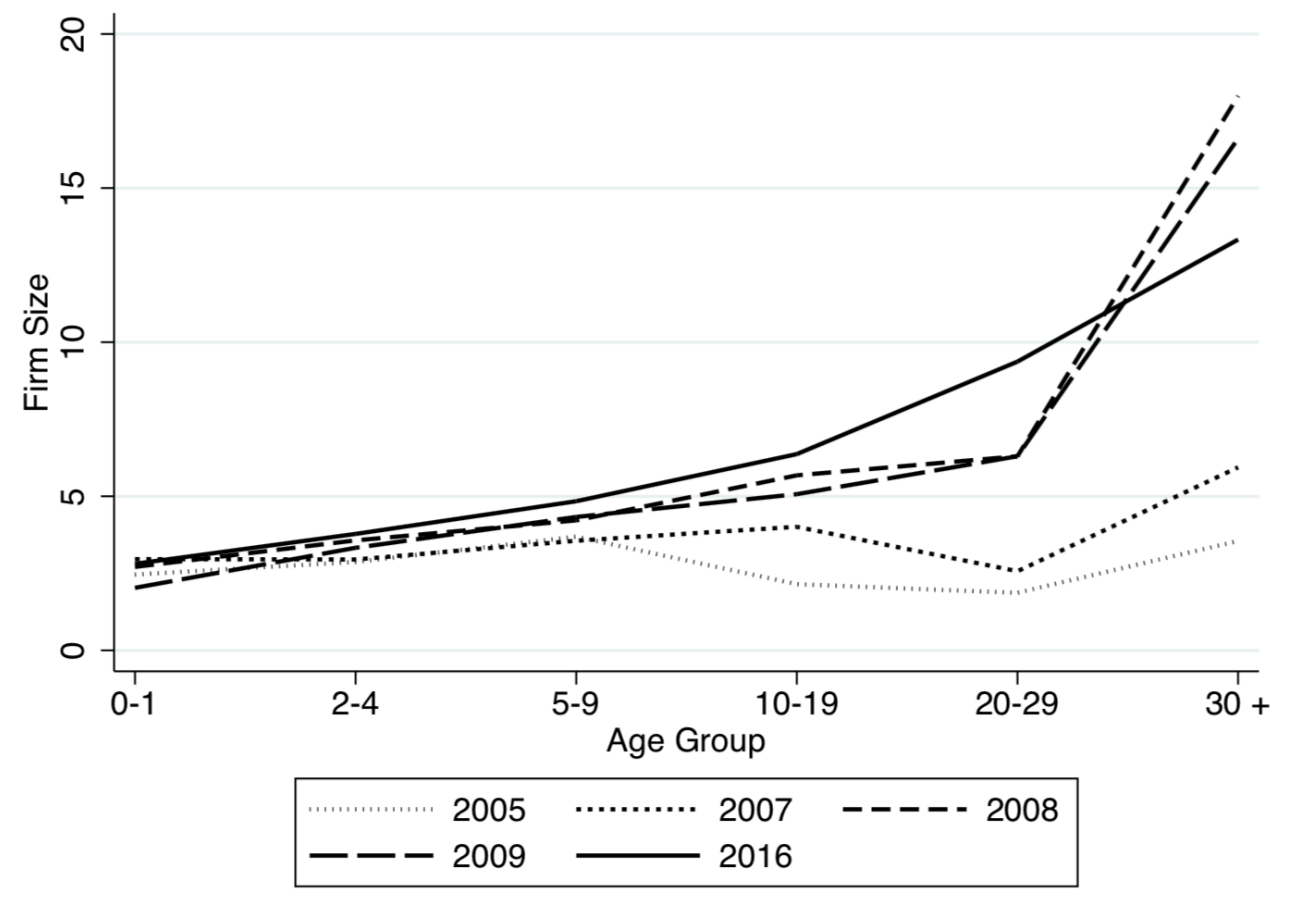

Figure 7. Tracking the Age Groups, 2005-2016

Source: TURKSTAT - Micro Data Collections

Table 7 portraits Turkish firms regarding the age groups nominated above. In 2005, the first thing to notice is that the youngest age group is the largest one, followed by 5-9 group. Both of these placements, young being the most dominant group and 5-9 exceeding the 2-4, are specific to 2005. 20-29 age group has the lowest mean size with 1.87 employees per firm not only in 2005, but in the whole period. Moreover, 5-9 age group has a mean size larger than 30 or more age firms. When we date these firms' origins to follow get closer with findings in Geroski, Mata and Portugal (2010), it clears the mystery yet demanding a conclusive research. The smallest sized 20-29 group were founded between 1976-1985, first 5 years 
including an embargo, domestic turbulence, coup d'etat, and second 5 years under military partly in control. Firms emerged in this period could be thought of a mostly subsistence oriented, or at least coded in a stability seeking nature. The 5-9 age group dates to 1996-2000 period. This group of firms has entered the Turkish economy in a turbulent inflationary and high government spending period with high interest rates, yet survived through 2001 crisis. So, it should not be a surprise for these firms being tough and versatile, achieving a larger size than their companions. As for the 30 or more age group, founded before 1975, they originate from a planned economic environment with a low portfolio of skilled workers. Firms of this era were nurtured by the government protection with import substitution industrialization perspective, yet a handful of them grow and get corporate while most businesses in the country simply aim subsistence and daily trade.

There is a serious drop in numbers of 0-1 age group in 2007, and the majority in groups transfers to 2-4 age firms. The abnormal small mean size of 20-29 age group continues. Total count of oldest firms shows a significant decrease, with pointing to that small and inefficient ones starting to drop out finally.

In 2008, 0-1 age group gets hit further and become the third most populated group in the economy with both aging of the members and decreasing number of entrants as shown in Table 3. The age groups finally depict a continuously increasing mean size starting from 2008. As successful and large firms from lower ages join, and small and inefficient ones drop out, 30 or more age group shows a significant increase in mean size reaching almost 18 .

From 2008 to 2009, a noticeable decrease in all age groups but 5-9 occurs. This decoupling of the 5-9 age firms is not surprising, because of the survivors of 2001 crisis among them as mentioned before. The most significant loss of mean size is of 0-1 firms as expected with $33 \%$. Entrants during the crisis years are the most vulnerable ones who had to face the storm in such inexperienced times, yet the evidence from previous crisis entrants offer prospect to those who survive.

Table 7: Size Statistics of Age Groups, Selected Years

\begin{tabular}{ccccccc} 
Size Group & Obs. & Meana & Std.b & b/a & Skewness & Kurtosis \\
\hline $\mathbf{2 0 0 5}$ & & & & & & \\
\hline $\mathbf{0 - 1}$ & $1,047,848$ & 2.46 & 45.58 & 19 & 476 & 320,680 \\
$\mathbf{2 - 4}$ & 748,162 & 2.87 & 36.33 & 13 & 137 & 30,900 \\
$\mathbf{5 - 9}$ & 843,414 & 3.69 & 76.59 & 21 & 296 & 128,036 \\
$\mathbf{1 0 - 1 9}$ & 307,051 & 2.15 & 29.26 & 14 & 148 & 33,380 \\
$\mathbf{2 0 - 2 9}$ & 63,545 & 1.87 & 33.87 & 18 & 137 & 22,459 \\
$\mathbf{3 0 \leq}$ & 38,750 & 3.55 & 63.16 & 18 & 68 & 6,307 \\
\hline
\end{tabular}




\begin{tabular}{|c|c|c|c|c|c|c|}
\hline 2007 & & & & & & \\
\hline $0-1$ & 829,174 & 2.96 & 60.6 & 20 & 183 & 48,966 \\
\hline $2-4$ & 880,009 & 2.95 & 29.71 & 10 & 180 & 61,307 \\
\hline $5-9$ & 683,077 & 3.56 & 40.4 & 11 & 143 & 33,683 \\
\hline $10-19$ & 435,246 & 4.01 & 72.72 & 18 & 498 & 295,678 \\
\hline 20-29 & 77,488 & 2.57 & 27.22 & 11 & 75 & 7,743 \\
\hline $30 \leq$ & 26,269 & 5.94 & 163.53 & 28 & 79 & 7,434 \\
\hline \multicolumn{7}{|l|}{2008} \\
\hline $0-1$ & 610,664 & 2.71 & 87.25 & 32 & 593 & 380,645 \\
\hline $2-4$ & 854,831 & 3.57 & 40.57 & 11 & 484 & 337,251 \\
\hline $5-9$ & 791,442 & 4.22 & 36.15 & 9 & 106 & 21,015 \\
\hline $10-19$ & 542,133 & 5.68 & 151.73 & 27 & 569 & 371,029 \\
\hline 20-29 & 104,544 & 6.3 & 101.95 & 16 & 92 & 11,081 \\
\hline $30 \leq$ & 32,378 & 17.99 & 448.02 & 25 & 53 & 3,238 \\
\hline \multicolumn{7}{|l|}{2009} \\
\hline $0-1$ & 519,904 & 2.03 & 11.46 & 6 & 165 & 51,708 \\
\hline $2-4$ & 940,573 & 3.33 & 78.11 & 23 & 596 & 406,808 \\
\hline 5-9 & 818,374 & 4.33 & 35.85 & 8 & 107 & 21,616 \\
\hline $10-19$ & 747,208 & 5.07 & 129.86 & 26 & 658 & 501,622 \\
\hline $20-29$ & 120,333 & 6.3 & 100.97 & 16 & 89 & 10,406 \\
\hline $30 \leq$ & 36,456 & 16.61 & 422.85 & 25 & 56 & 3,625 \\
\hline \multicolumn{7}{|l|}{2016} \\
\hline $0-1$ & 860,644 & 2.81 & 18.98 & 7 & 71 & 8,510 \\
\hline $2-4$ & 832,449 & 3.78 & 27.98 & 7 & 131 & 33,646 \\
\hline 5-9 & 796,720 & 4.84 & 58.3 & 12 & 245 & 93,967 \\
\hline $10-19$ & 806,976 & 6.37 & 70.04 & 11 & 111 & 20,615 \\
\hline $20-29$ & 276,710 & 9.37 & 123.52 & 13 & 112 & 19,963 \\
\hline $30 \leq$ & 79,022 & 13.33 & 306.3 & 23 & 57 & 3,872 \\
\hline
\end{tabular}

Source: TURKSTAT - Micro Data Collections

At the bottom part of Table 7 size statistics of the age groups observed in 2016 can be found. Compared to their 2009 situation, 0-1 age firms are seen to recover to a healthier mean size. The second interesting fact is, however, 30 or older firms continued to shrink while their total count more than doubles as they were expected to grow further following their pre-crisis trend. Not to mention that previously noticed stagnant 1976-1985 born firms now entered to the 30 or more age group. At the same time, 20-29 age group achieved a 
superior growth in the post-crisis period with almost 50\%. These cohorts are born in 19871996, which is a quite characteristic era with liberal economic policies, starting with ended military administration, liberating the international capital movements and ending with joining to the customs union of the European Union. These firms survived and gained experience with 1994 and 2001 crises of Turkey, justifying their outstanding performance. On the other hand, the first four age groups are almost having equal members in 2016. This uniformity informs a loss of dynamism because expanding older age groups should depict a favorable economic environment hence new firms seek entrance. On the contrary to seemingly consecutive high number of entrants during 2014-2016 as seen in Table 3, these figures are even behind 2005 values. The thrust and power coming from new firms are missing at the end of the subjected period, making the age distribution of Turkish firms closer to uniform.

\subsection{Density Estimations}

Figure 8 plots the size distribution of the age groups outlined in Table 7. It should be possible to track the evolution of specific groups by looking at their density estimations. The years are denoted in the vertical line labels.

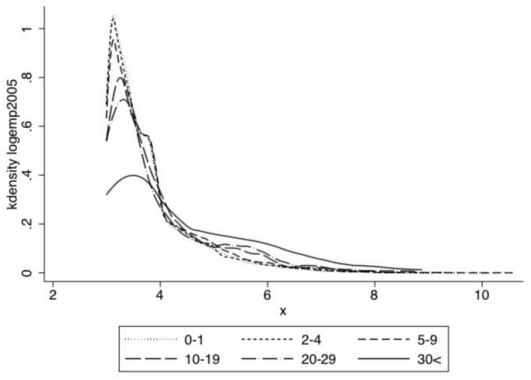

(a)

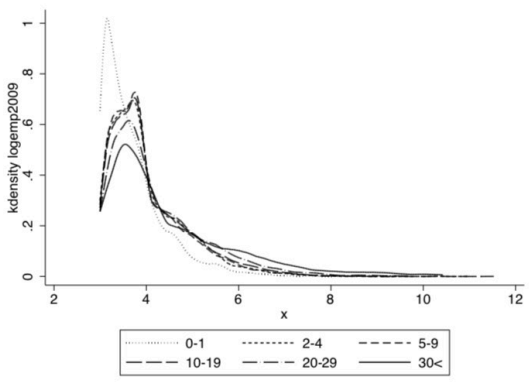

(c)

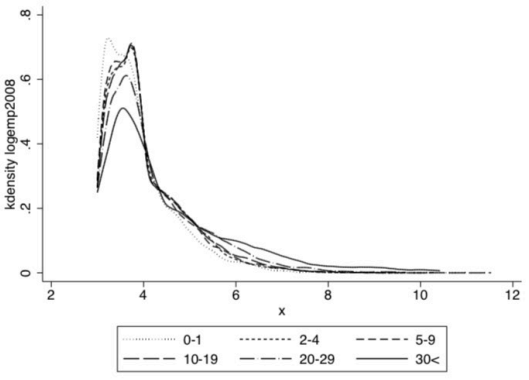

(b)

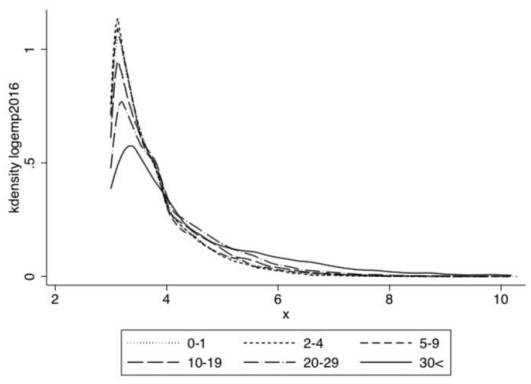

(d)

Figure 8. Size Distribution of the Age Groups, Selected Years

Source: TURKSTAT - Micro Data Collections 
Alongside with the previous literature, Figure 8 provides evidence that size distribution of firms by age groups depict a more symmetrical plot as the age increases. However, crisis years of 2008 and 2009 differ significantly among similar age distributions of other years. These two years' distribution plots get a more uniform shape in the center, indicating outlier firms with extremely smaller and larger sizes than the mean suffers from selection, or went into restructuring. Moreover, in these two years, middle age groups have two peaks with a taller one on the right. This means that small firms are wiped out and marginally larger ones survived from those distributions, as noted before. This indicates there is a possible safe size for a firm to be attained in order to survive the crisis.

Figure 8c shows how extremely skew is the size distribution of youngest firms in 2009 compared to others. This age group shows a wider medium sized distribution in 2008, but mainly keeps the skew shape. There are almost no big firms (with size above 100) entering to the economy in 2009, unlike 2008, meaning a great absence of large scale investments. On the other hand, the oldest group in the distribution evolves toward a steeper peaked shape, indicating an increase in small sized firms' weight in the distribution. This was also noted earlier as 30 or older firms in 2016 possess a decreasing mean size in the post-crisis era.

\section{CONCLUSION}

It is shown that despite a thrust from entering firms until the Global Financial Crisis in 2008, Turkish private sector got hit seriously and could not recover until 2013. When the post-crisis data is examined, despite the expansion among older firms, there are simply not enough new firms entering to the Turkish economy relative to its size. In 2016, age distribution of firms is almost uniform for the groups with a history of less than 20 years. Loss of dynamism and risk appetite is evident in this period. Combining with the shrinking mean size of oldest age group, there is a not-so-obvious inference: risk aversion and economic distrust keep productive people in paychecks while these lack of competition and availability of affordable professionals extend the lifetime of old and inefficient firms. These otherwise-entrepreneur productive employees could even bring the opportunity of lowering the excess size to the existing firms without self-improvement which may further explain the oldest firms' shrinking sizes. To keep in line with the scope of this paper, further comments related to policy problems and supporting evidence from macroeconomic variables are waived.

As asserted by Akcigit et al. (2016) it is evident from Table 7 that as Turkish firms get older, they do not necessarily grow larger. In fact, mean size of 30 years and older firms decreased significantly in the last decade. Further striking fact of this assertion is about the previous trend of the same statistic. The oldest Turkish firms, aged 30 and more, extensively grew until the crisis in 2008. This may indicate a shift of vision, or shift in the managerial ability as the paper explains. In the light of the proposed model, Global Financial Crisis in 2008 might 
have derailed Turkish private sector. Building further on the findings by Akcigit et al. (2016), it could be possible to claim that Turkish economic environment resembled a non-developed country until 2013 in terms of selection not functioning properly. During 2012 and 2013, many small sized but older firms get out of business. Combining with the previous assertion of oldest age groups, the shock of the crisis that disturbed the economic environment have not get stabilized until clearing the inefficient firms in 2013. In 2016 data of the oldest firms, it is seen that their mean size shrinks further which again turns the table towards the lack of selection in Turkey. This might coincide with the findings of Kiliçaslan and Taymaz (2009) on the policy grounds. As a further study, it should be interesting to assess whether policy responses to the effects of the Global Financial Crisis in Turkey had increased labor market flexibility leading to the diminishing of the selection afterwards. Clearly, employing mainstream theories to foresee the crisis among Turkish private sector would fail. Aim to capture these special aspects puts more importance on the new and more flexible approaches like $\mathrm{ABC}$ models where incorporating heterogeneity of units is much simple and valued.

2010 was a year lacking firm formation of small to medium size. It was a year with mean entrants is 1 with a little total variance. This might be strikingly pointing to the fact that jobs lost in 2008 (and 2009) crisis could turn into new firms with sole employees to seek subsistence, demanding theoretical background. Furthermore, Turkish firms laying their employees off during the crisis could have been created a serious competition against them with laid-off workers taking chances with entrepreneurship using their experience. It concurs with the evidence from age data of the closing firms after crisis years as cited above. This is an uncharted territory in economic theory, but there is evidence of the reverse. Reisenbichler and Morgan (2012) explain how the German firms kept their employees and turned a crisis to a "miracle".

Despite the low and close mean firm size among entrants after 2011, plots in Section 4.2 made clear of the recovery according to the statistics in the last years. This finding emphasizes the complementarity of the methods carried out in this study.

Thinking a business entity apart from its entrepreneur can be misleading. This drawback is inevitable under modeling with the rationality assumption, since the business owners are not obliged to be rational if there is no punishment through selection. Especially in non-developed economies where delegating managerial issues are shown to be uneasy, responses to certain shocks and decision-making processes resemble the vision of the founder of the firm. It is humbly claimed in this study that it can be misleading to model these processes without accounting for the heterogeneity caused by originating environment. Firms born during a certain atmosphere in a country where managerial hiring is found troublesome might not renew their way of doing things, apart from innovation, even if the world surrounding them changes drastically. They might even avoid selection in big numbers. In accordance with the findings of Geroski, Mata and Portugal (2010), models should also incorporate cohort 
characteristics as a meso source of variation, on top of the individual micro characteristics and macro level policy interactions.

Based on these essential findings of this study, policy-makers should consider promoting entrepreneurship for those who have higher abilities in order to achieve larger firms. There is a significant lack of competition in certain times, especially when productive people are tied to old but inefficient firms. By looking at the age plots and tables in Section 5, future steps regarding the shaping of the business firms can be based on lessons derived from late 80 s and early 90 s as those are the most successful firms in Turkey at all times. The extraordinarily small size of entering firms require special attention for policy-making. A better business environment to collide more entrepreneurs together can be useful. This might be achieved only with the help of NGOs such as TUSIAD or TOBB in cooperation with legislators. As seen from the data, most of the enterprises in Turkey are historically being formed in order to maintain subsistence. Elevating the characteristics of the majority of the ventures require better social governance which emerges from diversity of energetic organizational bodies.

\section{REFERENCES}

Acemoglu, D. (2012). Introduction to economic growth. Journal of Economic Theory. 147(2), 545-550.

Adelino, M., Ma, S. \& Robinson, D. (2017). Firm age, investment opportunities, and job creation. The Journal of Finance. 72(3), 999-1038.

Akcigit, U., Alp, H. \& Peters, M. (2016). Lack of selection and limits to delegation: firm dynamics in developing countries. National Bureau of Economic Research. No: 21905. https://www. nber.org/papers/w21905.

Angelini, P., \& Generale, A. (2008). On the evolution of firm size distributions. American Economic Review. 98(1), 426-438.

Audretsch, D. \& Mahmood, T. (1994). Firm selection and industry evolution: the post-entry performance of new firms. Journal of Evolutionary Economics. 4(3), 243-260.

Audretsch, D. \& Mata, J. 1995. The post-entry performance of firms: Introduction. International Journal of Industrial Organization. 13(4), 413-419.

Axtell, R. (2001). Zipf distribution of U.S. firm sizes. Science. 293 (5536), 1818-1820.

Aydogan, Y. \& Donduran, M. (2018). Estimations on the firm size distribution in Turkey. Journal of European Theoretical and Applied Studies. 6(2), 35-51.

Ayyagari, M., Juarros, P., Martinez Peria, M. \& Singh, S. (2016). Access to finance and job growth: firm-level evidence across developing countries. The World Bank Policy Research Working Paper No: 7604. http://documents.worldbank.org/curated/en/804.781.467990954208/ pdf/WPS7604.pdf 
Beck, T. \& Demirguc-Kunt, A. (2006). Small and medium-size enterprises: Access to finance as a growth constraint. Journal of Banking \& Finance. 30(11), 2931-2943.

Box, M. (2008). The death of firms: Exploring the effects of environment and birth cohort on firm survival in Sweden. Small Business Economics. 31 (4), 379-393.

Cabral, L. \& Mata, J. (2003). On the evolution of the firm size distribution: Facts and theory. American Economic Review. 93(4), 1075-1090.

Capelleras, J. \& Rabetino, R. (2008). Individual, organizational and environmental determinants of new firm employment growth: evidence from Latin America. International Entrepreneurship and Management Journal. 4(1), 79-99.

Cefis, E., Ciccarelli, M. \& Orsenigo, L. (2002). From Gibrat's legacy to Gibrat's fallacy. A Bayesian Approach to Study the Growth of Firms. Working papers at the Hyman Minsky Department of Economic Studies. 19.

Daunfeldt, S.O. \& Elert, N. (2013). When is Gibrat's law a law? Small Business Economics. 41(1), 133-147.

Delli Gatti, D., Desiderio, S., Gaffeo, E., Cirillo, P. \& Gallegati, M. (2011). Macroeconomics from the Bottom-up. Milan: Springer.

Evans, D. (1987a). The relationship between firm growth, size, and age: Estimates for 100 manufacturing industries. The Journal Of Industrial Economics. 35(4), 567-581.

Evans, D. (1987b). Tests of alternative theories of firm growth. Journal of Political Economy. 95(4), 657-674.

Evans, D. \& Leighton, L. (1989). Some empirical aspects of entrepreneurship. American Economic Review. 79(3), 519-535.

Galor, O. \& Michalopoulos, S. (2012). Evolution and the growth process: Natural selection of entrepreneurial traits. Journal of Economic Theory. 147(2), 759-780.

Geroski, P.A., Mata, J. \& Portugal, P. (2010). Founding conditions and the survival of new firms. Strategic Management Journal. 31(5), 510-529.

Gibrat, R. (1931). Les Inegalites Economiques. Paris: Sirey.

Harris, R. \& Trainor, M. (2005). Plant-level analysis using the ARD: Another look at Gibrat's law. Scottish Journal of Political Economy. 52(3), 492-518.

Henrekson, M. \& Johansson, D. (1999). Institutional effects on the evolution of the size distribution of firms. Small Business Economics. 12(1), 11-23.

Huergo, E. \& Jaumandreu, J. (2004). How does probability of innovation change with firm age? Small Business Economics. 22(3), 193-207.

Jovanovic, B. (1982). Selection and the evolution of industry. Econometrica. 50(3), 649-670. 
Kilıçaslan, Y. \& Taymaz, E. (2009). Labor market institutions and industrial performance: an evolutionary study. Cantner U., Gaffard J.L. \& Nesta L. (Ed.) Schumpeterian Perspectives on Innovation, Competition and Growth. (pp.207-222). Berlin: Springer.

Lucas, R. (1978). On the size distribution of business firms. The Bell Journal of Economics. 9(2), 508-523.

Pek, C. (2012). Firm size distribution and exporting behaviour: an empirical analysis of powerlaw behaviour of Turkish firms. (Unpublished master's thesis). L'Universite de Paris 1 Pantheon Sorbonne, Paris.

Piketty, T. (2000). Review of the book economic inequality and income distribution, by D. G. Champernowne \& F. A. Cowell. Economica. 67 (267),461-462.

Reisenbichler, A. \& Morgan, K. (2012). From "sick man" to "miracle": Explaining the robustness of the German labor market during and after the financial crisis 2008-09. Politics and Society. 40(4), 549-579.

Serrasqueiro, Z., Nunes, P., Leitão, J. \& Armada, M. (2010). Are there non-linearities between SME growth and its determinants? A quantile approach. Industrial and Corporate Change. 19(4), 1071-1108.

Tang, A. (2015). Does Gibrat's law hold for Swedish energy firms? Empirical Economics. 49(2), 659-674. 